Article

\title{
Direct and Indirect Effects of Literacy Skills and Writing Fluency on Writing Quality Across Three Genres
}

\author{
Gary A. Troia ${ }^{1, * \mathbb{D}}$, Julie S. Brehmer ${ }^{1}$, Kaitlin Glause ${ }^{2}$, Heather L. Reichmuth ${ }^{1} \mathbb{D}$ and \\ Frank Lawrence ${ }^{1}$ D \\ 1 College of Education, Michigan State University, East Lansing, MI 48824, USA; \\ brehmerj@michigan.gov (J.S.B.); reichmu1@msu.edu (H.L.R.); cougar@msu.edu (F.L.) \\ 2 English Department, Millikin University, Decatur, IL 62522, USA; kglause@millikin.edu \\ * Correspondence: gtroia@msu.edu
}

Received: 2 October 2020; Accepted: 19 October 2020; Published: 22 October 2020

\begin{abstract}
Data were collected for this study early in the school year to analyze the direct and indirect effects of word-level literacy skills (word recognition, spelling, and written vocabulary use) and handwriting fluency on writing quality across three genres of typewritten papers. We further explored whether typing fluency and text generation fluency mediated the effects. Finally, we examined whether there was any difference in the effects across three writing genres. Fourth and fifth graders $(N=175)$ from 21 typical classrooms in 12 different Midwestern U.S. schools participated. Regression path analyses were employed and revealed that word-level literacy skills had both significant direct and serial indirect effects on quality, via typing fluency and then text generation fluency (text length) when controlling for handwriting fluency. Further, handwriting fluency had no direct effect when controlling for word-level literacy skills but did have a significant serial indirect effect on writing quality via typing fluency then text generation fluency. Results indicate that handwriting fluency matters, even when composing on the computer. Stronger transcription fluency, particularly by hand, leads to higher quality writing, likely because less cognitive effort is devoted to transcription. This study adds to limited research on the cross-modal effects of transcription on writing quality.
\end{abstract}

Keywords: handwriting fluency; typing fluency; writing quality; serial mediation; path analysis

\section{Introduction}

The simple view of writing [1-3] postulates that writing is represented by an integrated array of knowledge and skills executed during writing tasks within one's limited capacity working memory. This array of knowledge and skills includes transcription (spelling, handwriting, and keyboarding), text generation (ideation and language formulation at the word, sentence, and discourse levels), and executive functions, initially supported by others, that coordinate transcription and text generation (e.g., conscious control of attention, concentration, and effort as well as flexible self-regulation of writing-related behaviors, thoughts, and emotions). Transcription skills and knowledge, in particular, are foundational to writing development and performance [4], as they exert a strong influence over the success of text generation processes in writing tasks (at least those that do not rely on dictation) due to limited cognitive capacity. Thus, unless and until transcription is automatized, written expression is likely to be more limited in length and quality [5-8].

\subsection{Relationships between Transcription and Writing Performance}

The importance of transcription is demonstrated by studies in which handwriting fluency and both isolated and contextual spelling proficiency have been found to explain a significant, non-trivial 
portion of variance in handwritten composition quality and quantity across different genres throughout grade school [9-15]. Moreover, teaching transcription by hand yields moderate to large effects for writing productivity and quality [16-18]. Likewise, keyboarding (i.e., typing) fluency has a significant association with word-processed compositional quality and productivity and keyboarding instruction produces at least modest effects on computer-generated writing performance [19-21]. Most relevant to the purposes of our study, handwriting fluency is positively correlated $(r=0.38)$ with word-processed composition quality and typing fluency is positively correlated $(r=0.44)$ with handwritten composition quality [20], meaning that, regardless of transcription mode, more fluent transcription by hand and/or by keyboard is associated with higher quality writing. However, research suggests that handwriting fluency may be only indirectly related to writing quality in older students cf. [13,22-24]. What remains unclear from the extant research, which we address here, is to what extent all these aspects of transcription (and other literacy skills) make direct and indirect contributions to writing quality, and do these contributions differ depending on the genre of writing produced. In particular, we are interested in examining how precisely handwriting and typing fluency (i.e., graphomotor fluency) influence computer-generated composition quality.

\subsection{Relationships between Aspects of Transcription}

There is evidence to indicate the varied aspects of transcription-spelling, handwriting, and keyboarding - are related because they rely to varying degrees on three integrated knowledge sources [19,25]: phonological (letter names and their associated sounds), orthographic (rules associated with combining individual letters and letter clusters to form words), and graphomotor (motor plans and movements required to produce written symbols). A meta-analysis performed by Feng, Lindner, Ji, and Joshi [10] observed a significant average weighted effect size of 0.561 for the relationship between handwriting and keyboarding fluency (accuracy plus speed) and 0.431 for the relationship between handwriting and keyboarding speed, but the effect size for the relationship between handwriting and keyboarding accuracy was not significantly different from zero. The four to five studies used to calculate these effect sizes included students in grades four and beyond, including adults. Overall, these few research studies indicate that students who possess weaker handwriting fluency also generally possess weaker keyboarding fluency, at least in the absence of adequate keyboarding instruction or a history of regular keyboard use cf. [26].

The meta-analysis conducted by Feng and colleagues [10] reported that neither the mean effect size for the association between spelling accuracy and handwriting fluency $(0.290)$ nor the mean effect size for the relationship between spelling errors and handwriting fluency $(-0.147)$ was significantly different from zero based on seven studies located, the majority of which included students in the primary grades. Spelling accuracy and errors were derived from writing samples rather than independent measures of spelling performance. Nevertheless, a study by Limpo, Alves, and Connelly [24], which was not included in the Feng et al. meta-analysis, found a significant correlation of 0.41 between handwriting fluency and composition spelling accuracy in a group of seventh and eighth-graders. The best-fitting model for the data suggested these were independent but correlated constructs, differentially associated with planning and translating, and their effects on opinion writing quality were fully mediated by the higher-level writing processes of planning and translating (at the sentence level). Studies describing relationships between keyboarding and spelling are relatively rare, but Cohen and Wicklund [27] reported a significant correlation of 0.37 between typing speed and spelling error recognition task performance among high school students. More recently, Jiménez and Hernández-Cabrera [28] reported significant correlations of about 0.30 between typing fluency tasks and dictated spelling accuracy tasks in first and second graders.

Of course, relationships between the three aspects of transcription, putatively due to reliance on shared knowledge resources in long-term memory, do not mean they are executed in the same manner or use these resources to the same degree. Handwriting, typing, and written spelling all require memorization and rapid recall of letter forms and planned sequential movements (graphomotor 
knowledge). In fact, evidence suggests letter forms are represented in long-term memory coupled with their associated motor movements derived through writing by hand but not typing [29-31]. Spelling, however, recruits additional phonological and orthographic information, though transcribing dictated material by hand or keyboard also recruits these knowledge resources because spelling is still involved. Thus, the nature of the transcription task is an important consideration-copying text and using retrieval of rote content such as the alphabet foreground graphomotor fluency and deemphasize (but do not eliminate) phonological and orthographic processing.

Handwriting employs a stylus to transcribe language, whereas keyboarding employs key presses (and recall of the locations of specific letter keys on the keyboard). Handwriting is believed to involve more temporally and spatially unified visual and haptic experiences than typing [32-34]. For instance, visual attention while typing (at least among those who have not developed touch typing skills) must be directed both at the screen and the keyboard, separating motor input from the visual output. This is a presumed reason for the observed positive effects on orthographic recall and encoding conveyed by handwriting but not typing noted by Longcamp and colleagues [29-32]. More generally, typing is executed with less precise motor control and coordination than handwriting, demonstrated by the sheer volume of typographic errors committed by most individuals. Consequently, while typing and handwriting speed and fluency do appear to be related, there is reason to believe they involve somewhat distinct graphomotor operations.

\subsection{Relationships between Other Literacy Abilities and Writing Performance}

It is important to acknowledge the contribution of other word-level literacy abilities to writing performance. The most obvious contributor is reading proficiency, because reading relies on phonological and orthographic knowledge sources, though not graphomotor. A recent meta-analysis reported by Kent and Wanzek [13] found correlations between reading performance and text length ranged from -0.08 to 0.69 across 16 samples with a total of 1306 individuals. The relationship was moderated by grade - a modest positive association was found for students in the primary grades (kindergarten through third grade) but an insignificant association was observed for students in grades four through six. Reading ability also predicts writing quality, and increasingly so as children grow older $[35,36]$. Of course, the relations between reading ability and writing performance are not unidirectional-development and/or instruction in one affects performance in the other [37-40]. A particular finding to note, because we capitalize on it in our study, is that word reading and spelling are highly correlated ( $r$ s often greater than 0.65 in primary and intermediate grades), much more so than reading and writing component skills at higher levels of language [35-37], leading Mehta and colleagues [41] to consider decoding and spelling a singular word-level literacy factor.

\subsection{Study Rationale}

Though there seem to be solid conceptual grounds for an association between graphomotor fluency and spelling, especially regarding the reinforcing effect handwriting appears to have on learning of spelling patterns, the empirical evidence is inconsistent. Spelling and word reading, on the other hand, have a well-documented and strong association. Thus, in this study, we combine dictated spelling accuracy, isolated word reading accuracy, and correct written vocabulary use to form a written language composite to represent word-level literacy abilities. We include vocabulary as a literacy component skill because it has been shown to make unique contributions to writing quality across grades [42-44]. Though handwriting and typing differ in motor execution and degree of visual-proprioceptive integration, correlations between these two modes of transcription have been observed. Yet, it is unclear how they operate in tandem to affect composition productivity and quality. Moreover, it is reasonable to assume that there are significant effects of handwriting fluency on keyboarded papers, but these effects may be mediated by more proximal transcription factors when writing on a computer, namely typing fluency. Consequently, our study aims to address the following three key research questions. First, to what degree do word-level literacy skills and handwriting 
fluency directly and indirectly influence the quality of typewritten papers? Second, are the effects of word-level literacy skills and handwriting fluency on typed papers mediated by typing fluency and text generation fluency? Third, are direct and/or indirect relationships between word-level literacy skills/graphomotor fluency and text quality replicated across different genres of writing? Although we have no particular reason to believe genre would influence the existence of any observed relationships, cognitive models of writing $[45,46]$ suggest that schemas for varied genres operate as a controlling influence on other writing processes during composing, and thus may influence the strength of the relationships. For example, a poorly elaborated writing schema associated with a less familiar genre would be expected to place more cognitive demands on the writer, resulting in weaker relationships between lower-level skills and writing performance because more variance would be attributable to the higher-level controlling influences [47].

\section{Materials and Methods}

\subsection{Participants}

A total of 175 students from grades $4(n=60)$ and $5(n=115)$, ages $9-0$ to $11-2$, participated. These students came from 21 general education classrooms distributed throughout 12 different Midwestern schools. The teachers were surveyed regarding aspects of their writing instruction. Out of the 21 teachers, only six reported devoting any instructional time to keyboarding or typing, between 10 and $60 \mathrm{~min}$ per week $(M=30.00, S D=18.97)$. Only one teacher reported devoting time (10 min per week) to handwriting instruction. Thirteen teachers reported spending any instructional time on spelling, between 5 and 80 min per week $(M=28.46, S D=24.27)$. The students in this study were recruited at the classroom level as part of a larger study of the relationships between teachers' writing instructional practices and annual growth in their students' writing performance, knowledge, and motivation. Of the participants, $52 \%(n=91)$ were female and $67.4 \%$ were White $(n=118)$. Additionally, about $10 \%(n=17)$ of the students were considered non-native English learners or students with disabilities (learning disability, ADHD, or autism) $(n=18)$. Participant data were collected in the first three months of the school year using procedures approved by the authors' institutional review board.

\subsection{Measures}

\subsubsection{Word Reading}

The Reading subtest of the Wide Range Achievement Test-3 [48] was administered to measure students' word recognition ability. Students were asked to read as many of the 42 words as possible on the test plate, which were presented in rows with increasing difficulty. Responses had to be given within $10 \mathrm{~s}$ and had to be correct whole-word pronunciations to be marked correct. Internal consistency reliabilities for the age group of students in this study range between 0.88 and 0.90 .

\subsubsection{Spelling}

The Spelling subtest of the Test of Written Language-4 [49] was given to students to evaluate their spelling ability. Students were presented with a series of dictated sentences they had to write. Each sentence was scored correct if all the written words were correctly spelled (though minor word substitutions were permitted, substituted words also had to be spelled correctly to receive credit). Obligatory capitalization also was considered part of spelling accuracy. A sentence fragment or major deviation from the dictated sentence was scored incorrect. The internal consistency reliabilities for the age group of students in this study range between 0.90 and 0.93 . 


\subsubsection{Written Vocabulary}

The Vocabulary subtest of the Test of Written Language-4 [49] was given to students to evaluate their vocabulary knowledge. Students were presented with a written word that they read independently and then created a sentence that incorporated the word, as written, to demonstrate their understanding of its meaning. Sentences were scored correct if a single sentence clearly displayed appropriate semantic use of the target word without altering its form; errors in other aspects of sentence writing (e.g., grammar, spelling) were not considered. The internal consistency reliabilities for the age group of students in this study range between 0.85 and 0.92 .

\subsubsection{Handwriting Fluency}

A paragraph copy task like the one developed by Monroe and Sherman [50] was used to measure handwriting fluency. A paragraph of 147 words and 602 characters (pilot testing indicated the original paragraph used by Monroe and Sherman required lengthening to avoid ceiling effects) was presented on a sheet of paper with widely spaced lines below it for copying the text. They were given $90 \mathrm{~s}$ to copy as much of the paragraph as possible and reminded that it was not necessary to read the text before copying it. The number of characters correctly written (i.e., characters accurately copied in sequence excluding additions or substitutions) in the time allotted was calculated (see [11]). All students elected to copy the paragraph using manuscript print.

\subsubsection{Typing Fluency}

This task was a typed analog to the handwriting fluency task described above using a computer keyboard to type text into a text box below the paragraph presented on a desktop or laptop screen. Again, the number of characters correctly written in $90 \mathrm{~s}$ was calculated. This task was administered at least several days after the handwriting fluency task.

\subsubsection{Text Length}

The total number of words written for each typewritten text in response to a narrative, opinion, or informative prompt was automatically calculated by computer. Because the amount of time students had to compose was limited to $15 \mathrm{~min}$, text length in our study best represents text generation fluency.

\subsubsection{Writing Quality}

Participants' typewritten texts (see below for details regarding how texts were elicited) were hand-scored using a rubric based on the Smarter Balanced Assessment Consortium performance task writing rubrics. The rubric contains seven dimensions: (1) reader orientation to purpose, (2) logical coherence, (3) concluding section, (4) cohesion through linking words or phrases, (5) development of ideas using details such as facts, examples, quotes, and experiences, (6) precise and varied language; and (7) correct grammar/usage/mechanics (i.e., writing conventions). Each dimension was scored on a scale of 0 (no evidence of dimensional quality, severely flawed/incomprehensible) to 5 (excellent evidence of dimensional quality, virtually no flaws/fully comprehensible) for a total score between 0 and 35. Each paper was initially read without scoring to obtain an overall impression of writing quality and to initially segregate the papers into high-, medium-, and low-quality subsets to expedite scoring using the rubric, a common practice in large-scale writing assessments [51]. Then, all papers were scored on each dimension in succession, beginning with writing conventions and ending with reader orientation to purpose, until scores for all seven dimensions were assigned. For this study, we excluded the dimension scores for writing conventions to enable a stricter test of our hypotheses. The remaining six dimension scores loaded on a single factor that accounted for $55.6 \%, 61.8 \%$, and $61.4 \%$ of the total variance for narrative, opinion, and informative papers, respectively. Internal consistency reliabilities using the six dimensions were $0.81,0.85$, and 0.87 for narrative, opinion, and informative papers, respectively. All of the papers were double scored by trained undergraduates and the interrater 
reliability estimates, calculated with a two-way random effects intraclass correlation (ICC), were 0.85 for each of the three genres using absolute agreement.

\subsection{Writing Tasks}

All tasks in this study were administered by one or two of the first four study authors to groups of 6 to 15 students. After completing the norm-referenced tests of word reading, spelling, and written vocabulary, and the timed handwriting fluency copying task, students were asked to respond to one writing prompt each for narrative, opinion, and informative genres (in that order) on a computer or laptop and to complete the typing fluency copying task on the same equipment using a web-based application called Writing Architect 1.0 [52]. Except for word reading, all tasks in this study were group administered. Students were encouraged to complete the handwriting fluency task after each time they wrote a paper to improve their performance, but this was not mandatory; thus, for most students, the data reported for this task are the average of two or three attempts. The writing prompts were administered over a period of several days so that students did not complete all three in one sitting. For each writing prompt to which students responded, they were given a printed copy of materials they viewed on the computer screen as well as a blank space below the printed prompt instructions for planning their papers (they were instructed to plan in whatever fashion they had been taught for the genre). Students were permitted up to three minutes to plan each paper and $15 \mathrm{~min}$ to write. When writing using Writing Architect 1.0, all accessibility and auto-correction word processing features are disabled. For planning, a countdown clock appeared in the lower-left corner of the screen; the prompt instruction page automatically advanced to the next screen page (informing the students they were going to be given $15 \mathrm{~min}$ to write a paper in response to the prompt they had been assigned in a blank text box on the next screen page; students had to manually advance to the text box screen page to begin writing) after the maximum time elapsed, but students could advance to the next screen page if they did not wish to plan or finished early. For writing, an audible beep paired with a visual warning flashed across the top of the screen was given when one minute remained. Just as for planning, students could advance to the next screen page if they completed their writing before the 15 min elapsed. All instructions (and passages for informational papers, see below) were not only presented in print and on the computer screen, but also were audibly presented by the computer to help alleviate problems encountered by weaker readers. Students were provided with headphones to listen simultaneously while reading the hard copy and/or electronic versions of materials.

Each genre had four prompt options and one option from each genre was randomly assigned to each student. The prompts (and task instructions noted below) were reviewed by an expert panel of writing researchers and teachers. Narrative prompts were in the form of a story title: (1) One Day of Invisibility; (2) The Attack; (3) Fantastic Voyage; (4) Don't Go into The Attic. Opinion prompts were in the form of a question: (1) Should sugary foods be allowed at school?; (2) Should a person always be honest?; (3) Should cellphones be allowed in classrooms?; (4) Should families be able to pick who their children's friends are? Informative prompts were linked to modified expository passages from online sources. The passage titles were: (1) 13-Year-Old World War II Veteran; (2) Swat Up: Six Reasons to Love Flies; (3) Can an Elevated Bus Solve China's Traffic Woes?; (4) Plastic Bottle Village. Permission was obtained from the copyright holders to use and modify the passages for research. The passages were modified to be within a range of readability appropriate for grades 3 through 8 based on word count, Lexile ${ }^{\circledR}$, Flesch-Kincaid, and Coh-Metrix degree of narrativity (below $50 \%$ for each passage). A pilot study to evaluate the equivalence of these prompts with a sample of approximately 175 children in grades 3 through 8 found no significant differences in text length and quality (including conventions) associated with prompt in any genre.

When responding to a narrative prompt, students were told to "write a creative, fictional storya make believe story - to match the title; write a story others will find interesting and enjoyable to read and remember, a good story (1) establishes the setting, (2) develops the characters, (3) describes an exciting plot sequence that has a clear beginning event, character actions related to that event, 
and an outcome or conclusion, and (4) follows the rules of writing." When responding to an opinion prompt, students were told to "write a persuasive essay that convinces readers to agree with your answer to the question and remember, a good persuasive essay (1) clearly states your opinion, (2) gives detailed facts and personal experiences to support your opinion, (3) has a conclusion that helps your readers understand why they should agree with your opinion, and (4) follows the rules of writing." When responding to an informative prompt, students were told to "write an informative paper that will help others learn about the topic of the passage you read; be sure to use information from the article you just read to give reasons why it is important and remember, a well written informative paper (1) has a clear main idea and stays on topic, (2) includes a good introduction and conclusion, (3) uses information from the article stated in your own words plus your own ideas, and (4) follows the rules of writing."

\subsection{Data Analysis}

We first screened all measures for univariate normality and homogeneity of variance across grade, gender, and ability (students with a disability versus those without) groups. Except for handwriting fluency, which exhibited group variance heterogeneity (in this case, an appropriate alternative was used for inferential statistical tests), the data from the measures were normally distributed without extreme outliers and exhibited equivalent variances across groups. We also examined the scatterplots of residuals as a function of predicted values for all variables and the assumptions of homoscedasticity and linear relationships were valid in all cases. Means and standard deviations for all measures by grade, gender, and ability group are presented in Table 1. We then used one-way ANOVAs (with $\alpha=0.005$ to adjust for multiple hypothesis testing) to determine if there were group differences for any of the measures (see Table 1 for summary) and dependent samples $t$-tests to determine if students' writing fluency differed significantly by mode of production or if there were significant differences between genres with regard to text length or quality. Subsequently, we computed bivariate correlations for all the measures using the entire dataset; these are reported in Table 2. Statistical significance was set to $\alpha$ $=0.001$ after applying the Bonferroni correction for the experiment-wise error. Finally, we employed regression path analysis using the PROCESS v3.3 macro [53] for SPSS, which permits the evaluation of total direct, total indirect, and discrete indirect effects between antecedent (i.e., predictor) and consequent (i.e., outcome) observed variables. Path analyses were conducted separately for each genre to examine how written language skills, indexed by a composite of word reading, spelling, and vocabulary (see below), and handwriting fluency are related to writing quality, mediated by typing fluency and then text length. Figure 1 illustrates the proposed serial mediation model tested for each genre. It should be noted that because PROCESS allows examination of effects on a terminal consequent variable by only a single focus antecedent (the $X$ in Figure 1), any other focus antecedent variable must be treated as a covariate (the $C$ in Figure 1) and, subsequently, the two are switched (i.e., the covariate becomes the focal antecedent, and the original focal antecedent is treated as a covariate) to estimate the effects of both variables. Mathematically, this yields the same regression coefficients and direct and indirect effects as if the variables were entered simultaneously using structural equation modeling [53] (p. 144). 
Table 1. Means (and standard deviations) for study variables by group and mean comparisons.

\begin{tabular}{ccccccc}
\hline \multirow{2}{*}{ Variable } & \multicolumn{2}{c}{ Grade } & \multicolumn{2}{c}{ Gender } & \multicolumn{2}{c}{ Disability } \\
\cline { 2 - 6 } & $\mathbf{4}$ & $\mathbf{5}$ & $\begin{array}{c}\text { Male } \\
(\boldsymbol{n}=\mathbf{6 0})\end{array}$ & $\begin{array}{c}\text { Female } \\
(\boldsymbol{n}=\mathbf{1 1 5})\end{array}$ & $\begin{array}{c}\text { Yes } \\
(\boldsymbol{n}=\mathbf{1 8})\end{array}$ & $\begin{array}{c}\text { No } \\
(\boldsymbol{n}=\mathbf{1 5 7 )}\end{array}$ \\
\hline Word Reading & $109.68(12.73)$ & $105.15(13.10)$ & $107.85(13.09)$ & $105.66(13.12)$ & $96.50(13.29)$ & $107.89(12.61) *$ \\
\hline Spelling & $10.13(2.81)$ & $9.90(3.11)$ & $9.83(3.18)$ & $10.12(2.85)$ & $6.61(2.91)$ & $10.37(2.77) *$ \\
Written Vocabulary & $10.92(2.51)$ & $10.92(3.25)$ & $11.10(3.24)$ & $10.76(2.78)$ & $8.11(2.61)$ & $11.24(2.89) *$ \\
HandwritingFluency & $98.77(23.38)$ & $110.98(28.84) *$ & $103.88(28.45)$ & $109.47(26.72)$ & $84.17(27.82)$ & $109.38(26.48) *$ \\
Typing Fluency & $84.32(42.16)$ & $95.10(37.50)$ & $94.81(41.06)$ & $88.46(37.75)$ & $62.45(37.60)$ & $94.50(38.39) *$ \\
Narrative Length & $128.87(75.40)$ & $145.31(69.75)$ & $131.34(68.27)$ & $147.18(74.60)$ & $70.38(52.24)$ & $147.03(69.90) *$ \\
Narrative Quality & $11.86(3.86)$ & $12.63(3.38)$ & $11.81(3.43)$ & $12.87(3.62)$ & $8.56(2.71)$ & $12.77(3.40) *$ \\
Opinion Length & $76.85(49.10)$ & $113.69(61.32) *$ & $87.99(54.44)$ & $113.08(62.40)$ & $64.14(54.04)$ & $104.89(59.41)$ \\
Opinion Quality & $11.55(4.47)$ & $13.18(3.84)$ & $11.69(3.90)$ & $13.47(4.16) *$ & $8.50(4.64)$ & $13.04(3.85) *$ \\
Informative Length & $83.17(56.51)$ & $93.81(55.26)$ & $85.55(57.22)$ & $94.37(54.39)$ & $58.71(38.97)$ & $93.30(56.27)$ \\
Informative Quality & $11.42(4.03)$ & $13.05(4.75)$ & $12.24(4.76)$ & $12.72(4.42)$ & $8.71(4.20)$ & $12.87(4.45) *$ \\
\hline
\end{tabular}

Notes: All variables were normally distributed within groups with no extreme outliers; ${ }^{*}$ indicates significant difference between groups at $p<0.005$ (Bonferroni adjusted value; the Brown-Forsythe robust test of equality of means was used when the assumption of homogeneity of variances was not met for handwriting fluency).

Table 2. Bivariate correlations between study variables.

\begin{tabular}{|c|c|c|c|c|c|c|c|c|c|c|c|}
\hline Variable & 1 & 2 & 3 & 4 & 5 & 6 & 7 & 8 & 9 & 10 & 11 \\
\hline 1. Word Reading & - & & & & & & & & & & \\
\hline 2. Spelling & $0.69 *$ & - & & & & & & & & & \\
\hline 3. Written Vocabulary & 0.63 * & 0.64 * & - & & & & & & & & \\
\hline 4. Hand. Fluency & 0.17 & $0.37^{*}$ & 0.31 * & - & & & & & & & \\
\hline 5. Typing Fluency & 0.41 * & $0.55^{*}$ & $0.40 *$ & $0.46^{*}$ & - & & & & & & \\
\hline 6. Narrative Length & 0.21 & $0.40 *$ & $0.27 *$ & $0.45^{*}$ & $0.68 *$ & - & & & & & \\
\hline 7. Narrative Quality & 0.50 * & $0.60 *$ & 0.49 * & 0.30 * & 0.53 * & 0.49 * & - & & & & \\
\hline 8. Opinion Length & 0.13 & $0.30 *$ & 0.26 & $0.39 *$ & 0.47 * & 0.64 * & $0.36 *$ & - & & & \\
\hline 9. Opinion Quality & $0.46^{*}$ & $0.60 *$ & 0.39 * & $0.38 *$ & 0.50 * & 0.49 * & $0.68 *$ & $0.51 *$ & - & & \\
\hline 10. Inform. Length & $0.29 *$ & $0.38 *$ & $0.44^{*}$ & $0.44^{*}$ & $0.56^{*}$ & $0.59 *$ & $0.45 *$ & $0.55 *$ & $0.45^{*}$ & - & \\
\hline 11. Inform. Quality & $0.48^{*}$ & $0.61 *$ & $0.57^{*}$ & 0.40 * & 0.53 * & $0.46^{*}$ & 0.64 * & 0.50 * & $0.63^{*}$ & $0.69^{*}$ & - \\
\hline
\end{tabular}

${ }^{*} p<0.001$ (Bonferroni adjusted value).

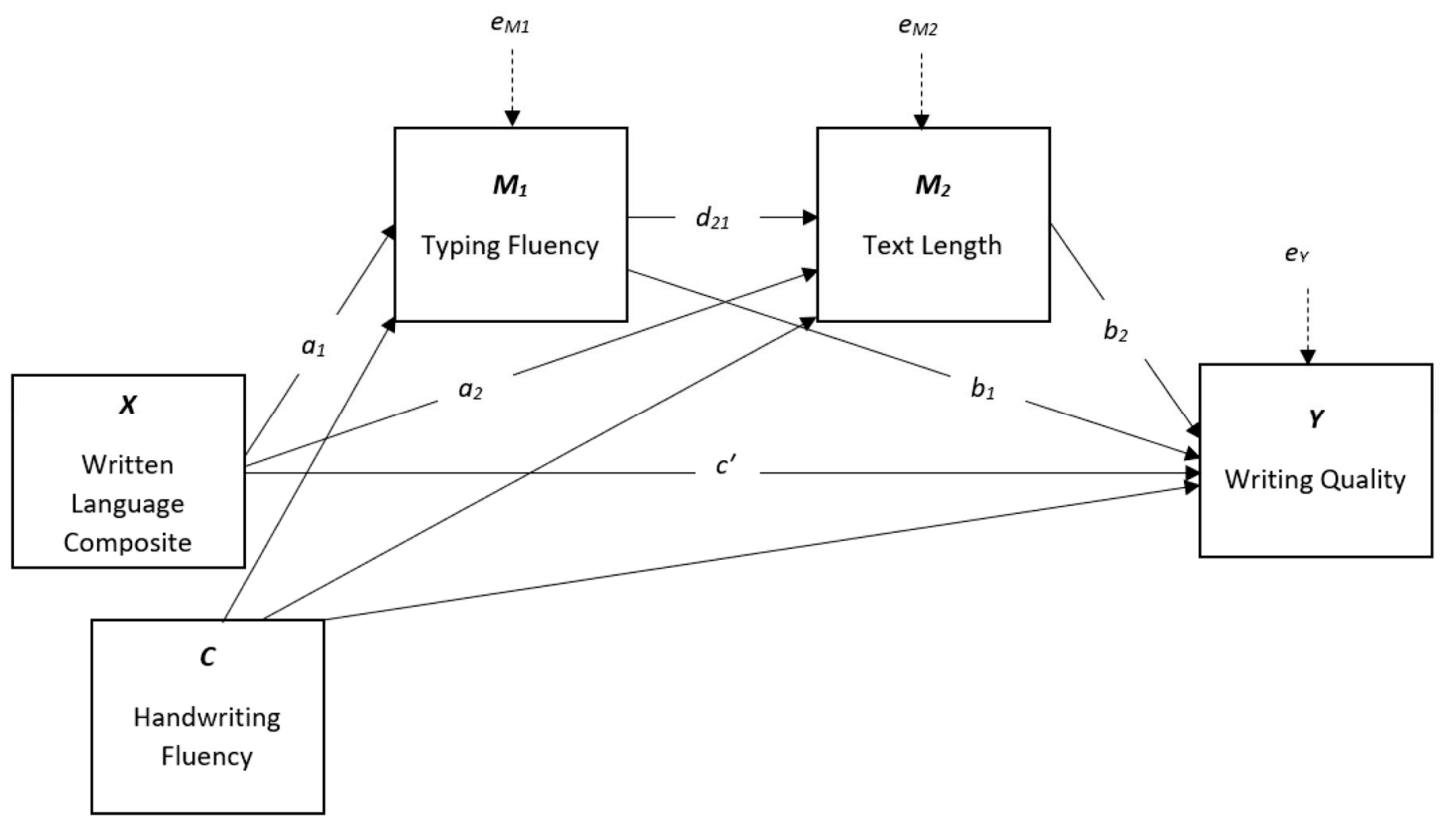

Figure 1. Proposed serial mediation model.

\section{Results}

\subsection{Group Comparisons}

As noted in Table 1, students with disabilities consistently performed significantly poorer on all measures compared to their peers without disabilities: word reading, $F(1,173)=13.14, M S E=159.90$, 
$p<0.001, g=-0.90$, spelling, $F(1,173)=29.56, M S E=7.72, p<0.001, g=-1.35$, written vocabulary, $F(1,173)=19.60, M S E=8.17, p<0.001, g=-1.09$, handwriting fluency, $\mathrm{F}(1,172)=14.48, M S E=708.33$, $p<0.001, g=-0.95$, typing fluency, $F(1,171)=13.05, M S E=1443.86, p<0.001, g=-0.90$, narrative paper length and quality, $F(1,167)=17.66$ and 22.04, MSE $=4732.42$ and 11.39, $p<0.001, g=-1.10$ and -1.24 , respectively, opinion paper quality, $F(1,169)=21.46, M S E=15.42, p<0.001, g=-1.22$, and informative paper quality, $F(1,157)=9.96, M S E=19.56, p=0.002, g=-0.85$. Girls performed better than boys with respect to opinion paper quality, $F(1,169)=7.97, M S E=16.60, p=0.012, g=0.43$, but did not significantly differ from boys otherwise. Fifth graders wrote longer, $F(1,169)=8.71$, $M S E=3916.20, p=0.004, g=0.48$, but not qualitatively better opinion papers than fourth graders. Fifth graders also exhibited greater handwriting fluency, $F(1,172)=7.99, M S E=733.87, p=0.005$, $g=0.45$, though not typing fluency.

\subsection{Transcription Mode and Writing Genre Comparisons}

We did find that handwriting fluency was significantly greater than typing fluency in our sample of students, $t(171)=5.82, p<0.001, d=0.47$. Additionally, students produced narrative papers that were significantly longer than opinion papers, $t(165)=8.19, p<0.001, d=0.54$, and informative papers, $t(156)=10.36, p<0.001, d=0.76$, and opinion papers that were significantly longer than informative papers, $t(156)=2.53, p=0.013, d=0.19$. However, paper quality was not significantly different across genres.

\subsection{Associations between Variables}

Table 2 illustrates that word reading, spelling, and written vocabulary scores from norm-referenced tests were all strongly positively correlated, sharing at least $40 \%$ variance; thus, we created a word-level Written Language Composite (WLC) for subsequent analyses by summing the scores from these three measures. Handwriting and typing fluency are significantly positively related to each other and to writing length and quality in each genre, though typing fluency is more strongly related to text length and quality when writing on a computer than handwriting fluency, as might be expected. Additionally notable is that the relationship between text length and quality is significantly weaker for narrative papers $(r=0.49)$ compared to informative papers $(r=0.69), z=-2.79, p=0.005$, and for opinion papers $(r=0.51)$ compared to informative papers, $z=-2.56, p=0.01$. Additionally, text quality across genres is generally slightly more strongly related than text length across genres.

\subsection{Predicting Narrative Writing Quality}

The results of regression path analysis to determine how written language skills transmit their effect to narrative writing quality through typing fluency and text length, while controlling for handwriting fluency, are presented in Table 3 (also see Figure 2 for a visual summary of results). As can be seen in this table and the associated figure, students with higher scores on WLC displayed stronger typing fluency $\left(a_{1}=0.851\right)$ but did not produce longer narratives $\left(a_{2}=-0.274\right.$, NS) when controlling for handwriting fluency. Conversely, typing fluency was not associated with story quality $\left(b_{1}=0.142\right.$, NS) but those students who wrote longer narratives did write better stories $\left(b_{2}=0.013\right)$ when controlling for handwriting fluency. Bootstrap 95\% confidence intervals based on 5,000 samples for the indirect effects of written language skills on narrative quality via typing fluency $\left(a_{1} b_{1}\right)$ and via text length $\left(a_{2} b_{2}\right)$ both included zero and thus represented no significant indirect effects. However, the bootstrap confidence interval for the mediation of the effects of written language skills on narrative quality via typing fluency and then text length $\left(a_{1} d_{21} b_{2}\right)$ was entirely above zero $(0.026,0.110)$ and thus represented a significant serial indirect effect. For every one standard deviation change in WLC controlling for handwriting fluency, there was a difference of about one-tenth of a standard deviation in story quality as a result of the total indirect effects. There also was evidence that students' WLC score was positively associated with narrative quality, independent of written language skills' effects on typing fluency or text length, but still controlling for handwriting fluency $\left(c^{\prime}=0.085\right)$; for every one 
standard deviation change in WLC, there was approximately four-tenths of a standard deviation change in narrative quality independent of the mediators. Overall, when controlling for handwriting fluency, typing fluency and text length together significantly mediated the relationship between WLC and narrative quality, and WLC had a significant direct effect on narrative quality as well. These antecedent variables explained approximately $45 \%$ of variance in narrative quality.

Also in Table 3 and Figure 2 are the results regarding how handwriting fluency transmits its effect on narrative writing quality through typing fluency and text length, while controlling for written language skills. Students with more fluent handwriting displayed stronger typing fluency $\left(a_{1}=0.527\right)$ and wrote longer narratives $\left(a_{2}=0.434\right)$ when controlling for WLC. The bootstrap confidence interval for the indirect effect of handwriting fluency on narrative quality via typing fluency $\left(a_{1} b_{1}\right)$ included zero and thus was not significant, but for the indirect effect via text length $\left(a_{2} b_{2}\right)$, the bootstrap interval did not include zero $(0.007,0.097)$ and thus did represent a significant indirect effect. The bootstrap confidence interval for the mediation of the effects of handwriting fluency on narrative quality via typing fluency and then text length $\left(a_{1} d_{21} b_{2}\right)$ was entirely above zero $(0.025,0.111)$ and thus represented a significant serial indirect effect. For every one standard deviation change in handwriting fluency controlling for WLC, there was a difference of about 0.17 standard deviation in story quality as a result of the total indirect effects. There was no evidence that students' handwriting fluency was positively associated with narrative quality independent of the mediators when controlling for WLC $\left(c^{\prime}=0.001\right.$, NS). Overall, when controlling for WLC, typing fluency and text length significantly mediated the relationship between handwriting fluency and narrative quality, but there was no significant direct effect of handwriting fluency on story quality.

Table 3. Regression path analysis for narrative quality outcome.

\begin{tabular}{|c|c|c|c|c|c|c|c|c|c|}
\hline \multirow[b]{3}{*}{ Antecedent Variables } & \multicolumn{9}{|c|}{ Consequent Variables } \\
\hline & \multicolumn{3}{|c|}{$M_{1}$ (Typing Fluency) } & \multicolumn{3}{|c|}{$M_{2}$ (Text Length) } & \multicolumn{3}{|c|}{$Y$ (Narrative Quality) } \\
\hline & Coeff. & $S E$ & $p$ & Coeff. & $S E$ & $p$ & Coeff. & $S E$ & $p$ \\
\hline X (Written Language) & 0.851 & 0.148 & $<0.001$ & -0.274 & .265 & 0.303 & 0.085 & 0.014 & $<0.001$ \\
\hline C (Handwriting Fluency) & 0.527 & 0.092 & $<0.001$ & 0.434 & .164 & 0.009 & 0.001 & 0.009 & 0.914 \\
\hline$M_{1}$ (Typing Fluency) & - & - & - & 1.147 & .127 & $<0.001$ & 0.142 & 0.008 & 0.078 \\
\hline$M_{2}$ (Text Length) & - & - & - & - & - & - & 0.013 & 0.004 & 0.001 \\
\hline \multirow[t]{2}{*}{ Constant } & \multicolumn{3}{|c|}{$\begin{array}{c}\mathrm{R}^{2}=0.344 \\
F(2,164)=42.933\end{array}$} & \multicolumn{3}{|c|}{$\begin{array}{c}\mathrm{R}^{2}=0.482 \\
F(3,163)=50.499\end{array}$} & \multicolumn{3}{|c|}{$\begin{array}{c}\mathrm{R}^{2}=0.447 \\
F(4,162)=32.774\end{array}$} \\
\hline & \multicolumn{3}{|c|}{$p<0.001$} & \multicolumn{3}{|c|}{$p<0.001$} & \multicolumn{3}{|c|}{$p<0.001$} \\
\hline \multicolumn{10}{|l|}{ (b) } \\
\hline & & & & \multicolumn{6}{|c|}{ Direct and Indirect Effects Decomposition } \\
\hline \multicolumn{4}{|c|}{ Effect } & $\begin{array}{l}\text { Standardized } \\
\text { Coeff. }\end{array}$ & \multicolumn{2}{|c|}{$\begin{array}{c}\text { Bootstrapped } \\
\text { SE }\end{array}$} & \multicolumn{2}{|c|}{$\begin{array}{c}\text { Bootstrapped } \\
95 \% \text { CI } \\
\text { Lower Limit }\end{array}$} & $\begin{array}{c}\text { Bootstrapped } \\
95 \% \text { CI } \\
\text { Upper Limit }\end{array}$ \\
\hline \multicolumn{7}{|c|}{ Total Effect (handwriting fluency covariate): $c \quad 0.517$} & \multirow{3}{*}{\multicolumn{2}{|c|}{0.033}} & \\
\hline \multicolumn{4}{|c|}{ Direct Effect (handwriting fluency covariate): $c^{\prime}$} & 0.413 & & & & \\
\hline \multicolumn{4}{|c|}{ Total Indirect Effect (handwriting fluency covariate): $c-c^{\prime}$} & 0.104 & \multicolumn{2}{|c|}{0.037} & & & 0.177 \\
\hline \multicolumn{4}{|c|}{ Indirect Effect $1\left(X \rightarrow M_{1} \rightarrow Y\right): a_{1} b_{1}$} & 0.058 & \multicolumn{2}{|c|}{0.033} & \multicolumn{2}{|c|}{-0.004} & 0.124 \\
\hline \multicolumn{4}{|c|}{ Indirect Effect $2\left(X \rightarrow M_{2} \rightarrow Y\right): a_{2} b_{2}$} & -0.018 & & & \multicolumn{2}{|c|}{-0.064} & 0.019 \\
\hline Indirect Effect 3( & $\rightarrow M_{1} \rightarrow \Lambda$ & $\rightarrow Y): a_{1}$ & & 0.063 & & & 0.0 & & 0.110 \\
\hline Cont & st 1 (IE1 - & & & 0.076 & & & 0.0 & & 0.146 \\
\hline Cont & st 2 (IE1 - & & & -0.005 & & & -0. & 995 & 0.082 \\
\hline Cont & st 3 (IE2 - & & & -0.081 & & & -0. & & -0.022 \\
\hline Total Effect (w) & ten langua & e covariat & & 0.174 & & & & & \\
\hline Direct Effect (w & tten langu & e covariat & & 0.007 & & & & & \\
\hline Total Indirect Effec & written las & uage cova & & 0.167 & & & 0.0 & & 0.259 \\
\hline Indirect $\mathrm{E}$ & et $1(X \rightarrow$ & $1 \rightarrow Y)$ & & 0.058 & & & -0. & 05 & 0.135 \\
\hline Indirect $\mathrm{E}$ & $2(X \rightarrow$ & $2 \rightarrow Y)$ & & 0.045 & & & 0.0 & & 0.097 \\
\hline Indirect Effec & $3\left(X \rightarrow M_{1}\right.$ & $\left.M_{2} \rightarrow Y\right)$ & & 0.063 & & & 0.0 & & 0.111 \\
\hline Cont & st 1 (IE1 - & & & 0.013 & & & -0. & 72 & 0.105 \\
\hline Cont & st 2 (IE1 - & & & -0.005 & & & -0. & 993 & 0.083 \\
\hline Cont & st 3 (IE2 - & & & -0.018 & & & -0. & 881 & 0.032 \\
\hline
\end{tabular}




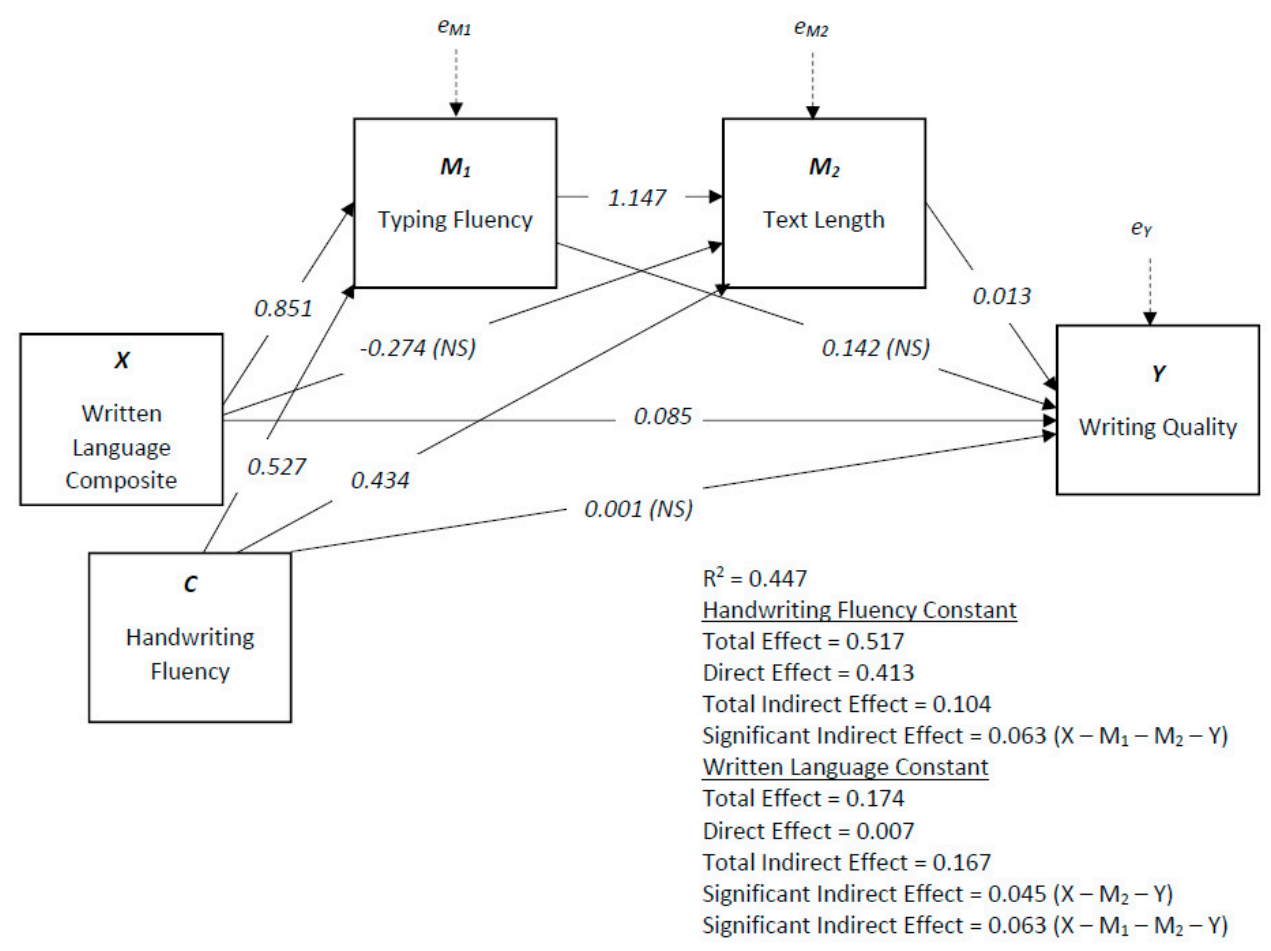

Figure 2. Serial Mediation Results for Narrative Quality.

\subsection{Predicting Opinion Writing Quality}

Table 4 (also see Figure 3) displays the results of the regression path analysis using opinion writing quality as the terminal consequent variable. As can be seen in this table and the associated figure, students with higher scores on WLC displayed stronger typing fluency $\left(a_{1}=0.860\right)$ but did not produce longer opinion papers $\left(a_{2}=-0.162\right.$, NS) when controlling for handwriting fluency. Conversely, typing fluency was not associated with opinion paper quality $\left(b_{1}=0.014\right.$, NS) but those students who wrote longer texts did write better opinion papers $\left(b_{2}=0.022\right)$ when controlling for handwriting fluency. The bootstrap confidence interval for the indirect effect of written language skills on opinion quality via typing fluency $\left(a_{1} b_{1}\right)$ did not contain zero $(0.001,0.102)$ and thus was significant, though the confidence interval for the indirect effect via text length $\left(a_{2} b_{2}\right)$ did include zero and consequently was not significant. The bootstrap confidence interval for the mediation of the effects of written language skills on opinion quality via typing fluency and then text length $\left(a_{1} d_{21} b_{2}\right)$ was entirely above zero $(0.024,0.091)$ and thus represented a significant serial indirect effect. 
Table 4. Regression path analysis for opinion quality outcome.

\begin{tabular}{|c|c|c|c|c|c|c|c|c|}
\hline \multirow[b]{4}{*}{ Antecedent Variables } & \multicolumn{4}{|c|}{ Consequent Variables } & & & & \\
\hline & \multirow{2}{*}{\multicolumn{3}{|c|}{$M_{1}$ (Typing Fluency) }} & \multirow{2}{*}{\multicolumn{3}{|c|}{$M_{2}$ (Text Length) }} & \multirow{2}{*}{\multicolumn{2}{|c|}{$Y$ (Opinion Quality) }} \\
\hline & & & & & & & & \\
\hline & Coeff. & $S E$ & $p$ & Coeff. & $S E$ & $p$ & Coeff. $S E$ & $p$ \\
\hline$X$ (Written Language) & 0.860 & 0.145 & $<0.001$ & -0.162 & 0.278 & 0.561 & $0.085 \quad 0.015$ & $<0.001$ \\
\hline C (Handwriting Fluency) & 0.498 & 0.092 & $<0.001$ & 0.532 & 0.174 & 0.003 & $0.014 \quad 0.010$ & 0.147 \\
\hline$M_{1}$ (Typing Fluency) & - & - & - & 0.638 & 0.135 & $<0.001$ & $0.014 \quad 0.008$ & 0.082 \\
\hline$M_{2}$ (Text Length) & - & - & - & - & - & - & $0.022 \quad 0.004$ & $<0.001$ \\
\hline \multirow[t]{2}{*}{ Constant } & -71.897 & 18.986 & $<0.001$ & $8.250 \quad 3$ & 34.418 & 0.811 & -3.4891 .896 & 0.068 \\
\hline & \multicolumn{3}{|c|}{$\begin{array}{c}\mathrm{R}^{2}=0.337 \\
F(2,166)=42.091 \\
p<0.001\end{array}$} & \multicolumn{3}{|c|}{$\begin{array}{c}\mathrm{R}^{2}=0.262 \\
F(3,165)=19.538 \\
p<0.001\end{array}$} & \multicolumn{2}{|c|}{$\begin{array}{c}\mathrm{R}^{2}=0.463 \\
F(4,164)=35.341 \\
p<0.001\end{array}$} \\
\hline \multicolumn{9}{|l|}{ (b) } \\
\hline & \multicolumn{8}{|c|}{ Direct and Indirect Effects Decomposition } \\
\hline \multicolumn{4}{|c|}{ Effect } & $\begin{array}{l}\text { Standardized } \\
\text { Coeff. }\end{array}$ & \multicolumn{2}{|c|}{$\begin{array}{c}\text { Bootstrapped } \\
S E\end{array}$} & $\begin{array}{l}\text { Bootstrapped } \\
95 \% \text { CI } \\
\text { Lower Limit }\end{array}$ & $\begin{array}{l}\text { Bootstrapped } \\
95 \% \text { CI } \\
\text { Upper Limit }\end{array}$ \\
\hline \multicolumn{7}{|c|}{ Total Effect (handwriting fluency covariate): $c \quad 0.446$} & & \\
\hline \multicolumn{7}{|c|}{ Direct Effect (handwriting fluency covariate): $c^{\prime} \quad 0.359$} & \multirow[b]{2}{*}{0.017} & \\
\hline \multicolumn{4}{|c|}{ Total Indirect Effect (handwriting fluency covariate): $c-c^{\prime}$} & 0.087 & \multicolumn{2}{|c|}{0.040} & & 0.175 \\
\hline \multirow{2}{*}{\multicolumn{4}{|c|}{$\begin{array}{l}\text { Indirect Effect } 1\left(X \rightarrow M_{1} \rightarrow Y\right): a_{1} b_{1} \\
\text { Indirect Effect } 2\left(X \rightarrow M_{2} \rightarrow Y\right): a_{2} b_{2}\end{array}$}} & 0.051 & \multicolumn{2}{|c|}{0.026} & 0.001 & 0.102 \\
\hline & & & & -0.015 & \multirow{2}{*}{\multicolumn{2}{|c|}{$\begin{array}{l}0.029 \\
0.017\end{array}$}} & -0.065 & 0.050 \\
\hline \multicolumn{4}{|c|}{ Indirect Effect $3\left(X \rightarrow M_{1} \rightarrow M_{2} \rightarrow Y\right): a_{1} d_{21} b_{2}$} & 0.052 & & & 0.024 & 0.091 \\
\hline \multicolumn{4}{|c|}{ Contrast 1 (IE1 - IE2) } & 0.066 & \multicolumn{2}{|c|}{0.037} & -0.014 & 0.134 \\
\hline \multirow{2}{*}{\multicolumn{4}{|c|}{$\begin{array}{l}\text { Contrast } 2 \text { (IE1 - IE3) } \\
\text { Contrast } 3 \text { (IE2 - IE3) }\end{array}$}} & -0.001 & & & -0.068 & 0.056 \\
\hline & & & & -0.067 & & & -0.140 & 0.010 \\
\hline Total Effect (wr & tten langua & covariate & & 0.268 & & & & \\
\hline Direct Effect (w & itten langu & e covariate & & 0.096 & & & & \\
\hline Total Indirect Effect & (written las & uage cova & & 0.172 & & & 0.081 & 0.290 \\
\hline Indirect $\mathrm{Ef}$ & ect $1(X \rightarrow$ & $\rightarrow Y Y)$ & & 0.046 & & & 0.001 & 0.099 \\
\hline Indirect $\mathrm{Ef}$ & ect $2(X \rightarrow$ & $\rightarrow Y)$ & & 0.079 & & & 0.011 & 0.079 \\
\hline Indirect Effect & $3\left(X \rightarrow M_{1}\right.$ & $\left.M_{2} \rightarrow Y\right)$ & & 0.047 & & & 0.021 & 0.081 \\
\hline Contr & st 1 (IE1 - & & & -0.033 & & & -0.140 & 0.050 \\
\hline Contr & st 2 (IE1 - & & & -0.001 & & & -0.060 & 0.056 \\
\hline Contr & st 3 (IE2 - & & & 0.032 & & & -0.045 & 0.141 \\
\hline
\end{tabular}

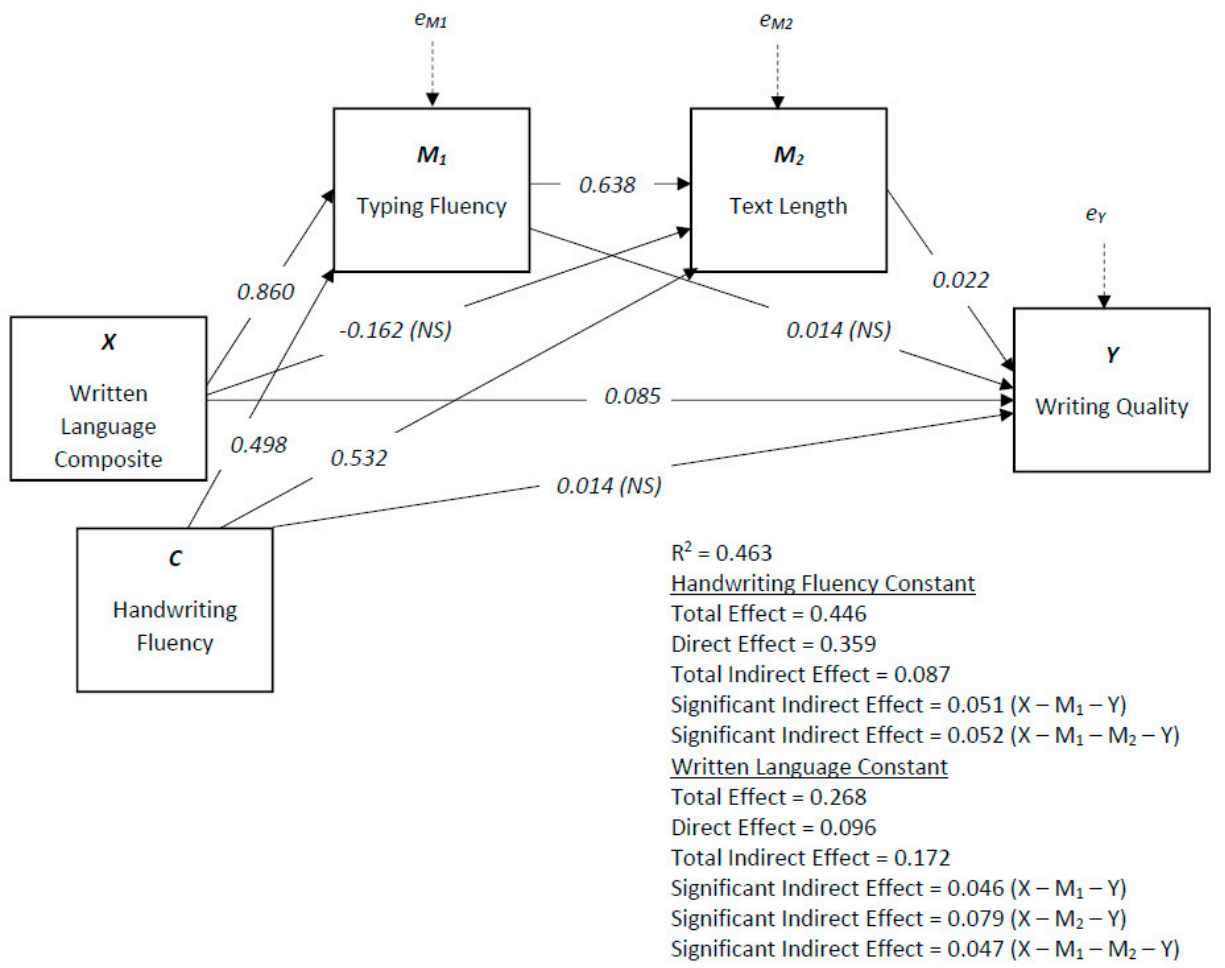

Figure 3. Serial Mediation Results for Opinion Quality. 
For every one standard deviation change in WLC controlling for handwriting fluency, there was a difference of about 0.08 standard deviation in opinion paper quality as a result of the total indirect effects. There also was evidence that students' WLC score was positively associated with opinion quality, independent of written language skills' effects on typing fluency or text length, but still controlling for handwriting fluency $\left(c^{\prime}=0.085\right)$; for every one standard deviation change in WLC, there was approximately a third of a standard deviation change in opinion quality independent of the mediators. Overall, when controlling for handwriting fluency, typing fluency and text length significantly mediated the relationship between WLC and opinion quality, and WLC had a significant direct effect on opinion quality as well. These antecedent variables explained approximately $46 \%$ of variance in opinion paper quality.

Table 4 and Figure 3 also give results regarding how handwriting fluency transmits its effect on opinion writing quality through typing fluency and text length, while controlling for written language skills. Students with more fluent handwriting displayed stronger typing fluency $\left(a_{1}=0.498\right)$ and wrote longer opinion papers $\left(a_{2}=0.532\right)$ when controlling for WLC. The $95 \%$ bootstrap confidence intervals based on 5,000 samples for the indirect effects of handwriting fluency on opinion quality via typing fluency $\left(a_{1} b_{1}\right)$ and via text length $\left(a_{2} b_{2}\right)$ were both significant as they did not contain the value of zero $(0.001,0.099$ and $0.011,0.079$, respectively). Moreover, the bootstrap confidence interval for the mediation of the effects of handwriting fluency on opinion quality via typing fluency and then text length $\left(a_{1} d_{21} b_{2}\right)$ was entirely above zero $(0.021,0.081)$ and thus represented a significant serial indirect effect. For every one standard deviation change in handwriting fluency controlling for WLC, there was a difference of about 0.17 standard deviation in opinion paper quality as a result of the total indirect effects. There was no evidence that students' handwriting fluency was positively associated with opinion quality independent of the mediators when controlling for WLC $\left(c^{\prime}=0.014\right.$, NS). Overall, when controlling for WLC, typing fluency and text length significantly mediated the relationship between handwriting fluency and opinion quality, but there was no significant direct effect of handwriting fluency on opinion quality.

\subsection{Predicting Informative Writing Quality}

Finally, the results associated with the regression path analysis using informative writing quality as the terminal consequent variable are presented in Table 5 and Figure 4. Students with higher scores on WLC displayed stronger typing fluency $\left(a_{1}=0.886\right)$ but did not produce longer informative papers $\left(a_{2}=0.365, \mathrm{NS}\right)$ when controlling for handwriting fluency. Conversely, typing fluency was not related to informative quality $\left(b_{1}=0.005, \mathrm{NS}\right)$ but those students who wrote longer texts did write better informative papers $\left(b_{2}=0.044\right)$ when controlling for handwriting fluency. The bootstrap confidence interval for the indirect effects of written language skills on informative quality via typing fluency $\left(a_{1} b_{1}\right)$ and via text length $\left(a_{2} b_{2}\right)$ included zero and consequently were not significant. The bootstrap confidence interval for the mediation of the effects of written language skills on informative paper quality via typing fluency and then text length $\left(a_{1} d_{21} b_{2}\right)$ was entirely above zero $(0.046,0.121)$ and thus represented a significant serial indirect effect. For every one standard deviation change in WLC controlling for handwriting fluency, there was a difference of about 0.16 standard deviation in informative paper quality as a result of the total indirect effects. There also was evidence that students' WLC score was positively associated with informative quality, independent of written language skills' effects on typing fluency or text length, but still controlling for handwriting fluency $\left(c^{\prime}=0.087\right)$; for every one standard deviation change in WLC, there was approximately a third of a standard deviation change in informative quality independent of the mediators. Overall, when controlling for handwriting fluency, typing fluency and text length significantly mediated the relationship between WLC and informative paper quality, and WLC had a significant direct effect on informative quality as well. These antecedent variables explained approximately $61 \%$ of variance in informative paper quality. 
Table 5. Regression path analysis for informative quality outcome.

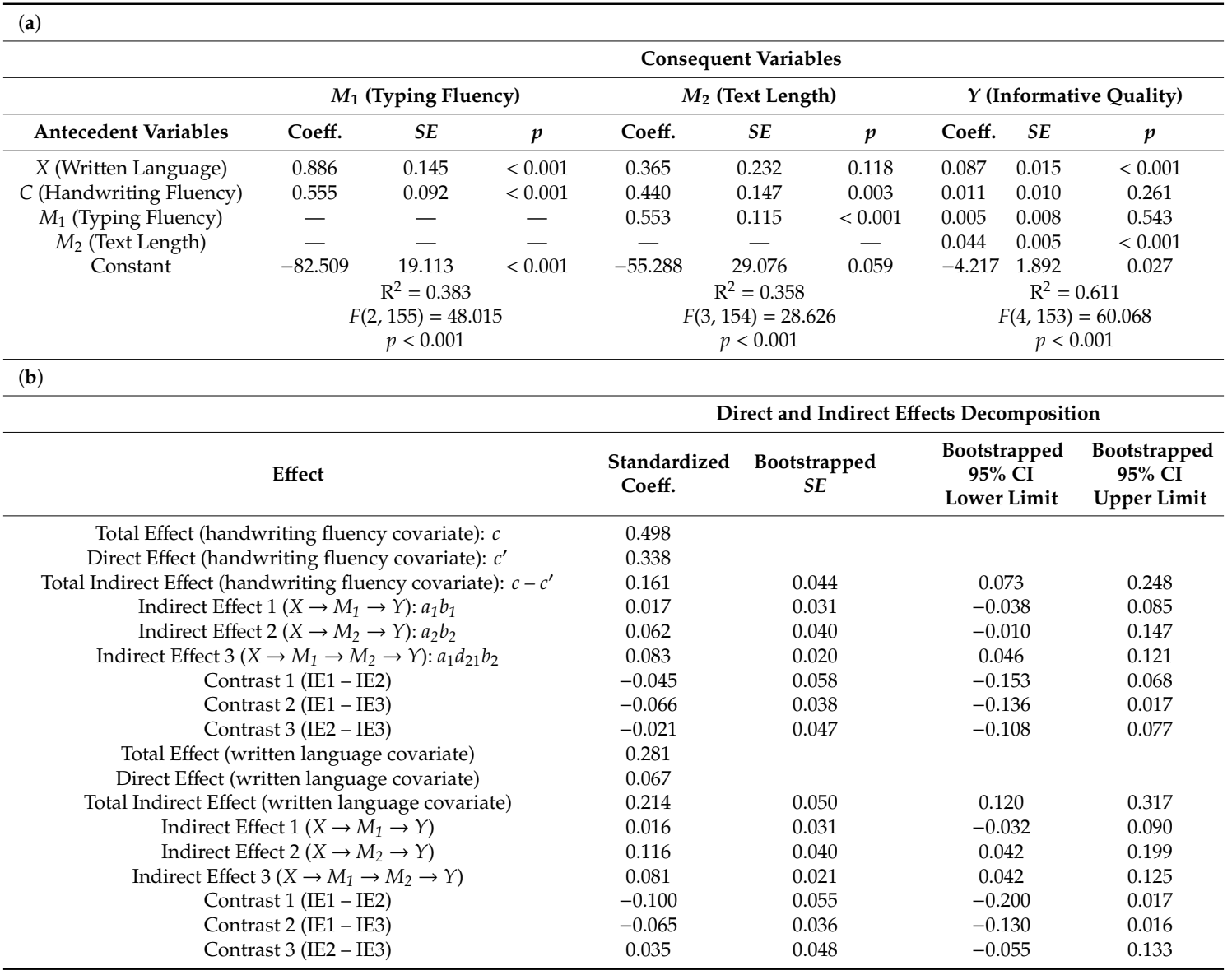

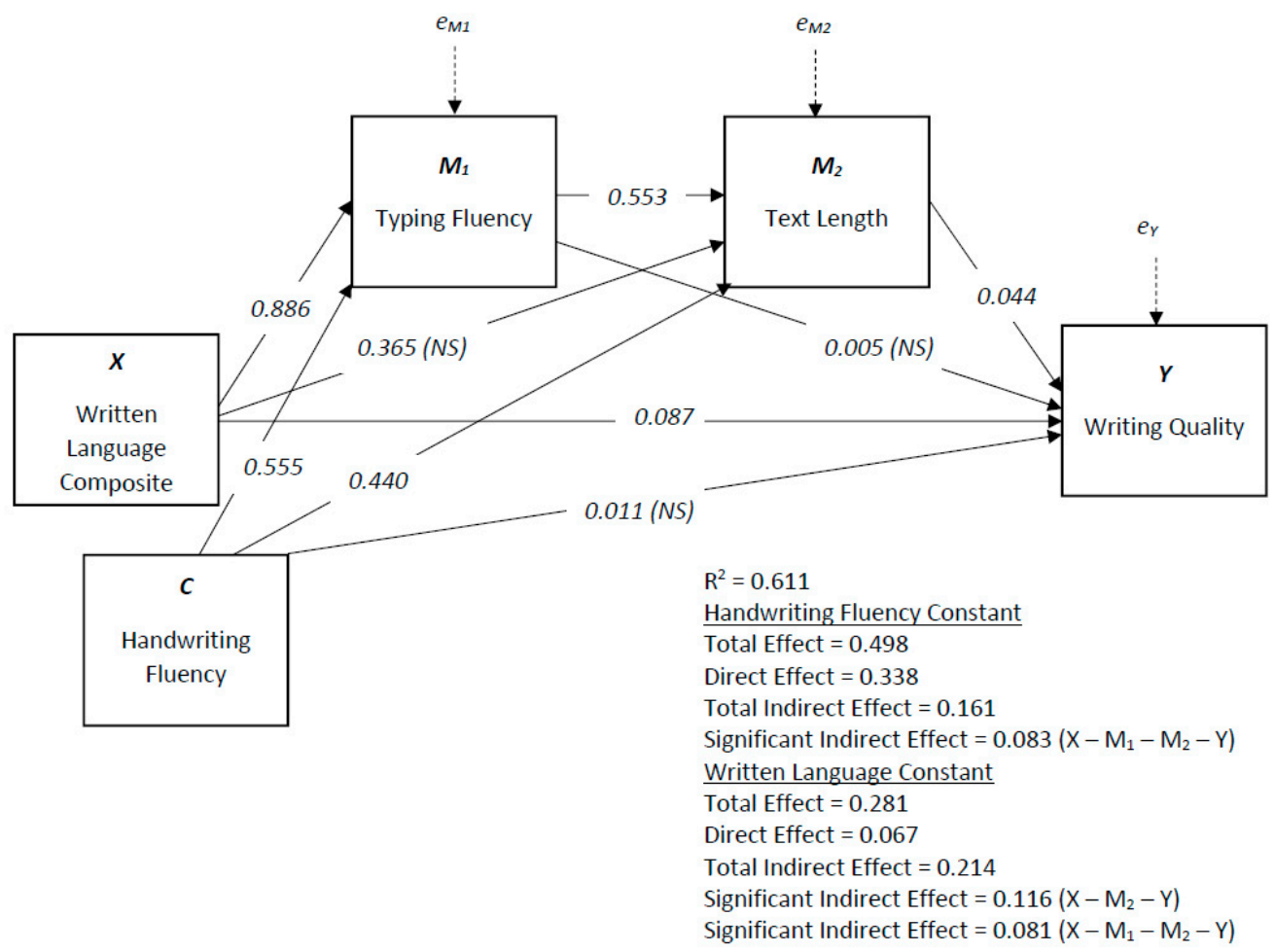

Figure 4. Serial Mediation Results for Informative Quality. 
Table 5 and Figure 4 also give results regarding how handwriting fluency transmits its effect on informative writing quality through typing fluency and text length, while controlling for written language skills. Students with more fluent handwriting displayed stronger typing fluency $\left(a_{1}=0.555\right)$ and wrote longer informative papers $\left(a_{2}=0.440\right)$ when controlling for WLC. The $95 \%$ bootstrap confidence interval for the indirect effect of handwriting fluency on informative quality via typing fluency $\left(a_{1} b_{1}\right)$ was not significant $(-0.032,0.090)$ but was for the indirect effect via text length $\left(a_{2} b_{2}\right)(0.042,0.199)$. Moreover, the bootstrap confidence interval for the mediation of the effects of handwriting fluency on informative paper quality via typing fluency and then text length $\left(a_{1} d_{21} b_{2}\right)$ did not include the value of zero $(0.042,0.125)$ and thus represented a significant serial indirect effect. For every one standard deviation change in handwriting fluency controlling for WLC, there was a difference of about two-tenths of a standard deviation in informative paper quality as a result of the total indirect effects. There was no evidence that students' handwriting fluency was positively associated with informative quality independent of the mediators when controlling for WLC $\left(c^{\prime}=0.011\right.$, NS). Overall, when controlling for WLC, typing fluency and text length significantly mediated the relationship between handwriting fluency and informative quality, but there was no significant direct effect of handwriting fluency on informative quality.

\section{Discussion}

In our sample of fourth and fifth graders from typical classrooms in the Midwestern United States, we found that, regardless of genre, a composite score representing word-level written language skills-word recognition, spelling, and written vocabulary use-has both a significant direct and a serial indirect (through typing fluency and then text length) effect on writing quality, when controlling for handwriting fluency. Overall, a one standard deviation change in the WLC corresponded to about a one-half standard deviation change in writing quality across genres, and about $20-32 \%$ of that change was due to indirect effects, depending on the genre. This finding implies two things. One, stronger component literacy skills enhance typewritten text quality; spelling, vocabulary, and reading performance each have been found to predict writing quality $[13,36,43,44]$. That is, students who possess greater breadth and depth in their vocabulary knowledge and who are more capable of decoding and encoding phonological and orthographic information can leverage these abilities to write better papers. Our quality scale included a dimension devoted to precise and varied language, which subsumes vocabulary use, and thus would be sensitive to individual variation in semantic skills such as vocabulary use. However, we excluded writing conventions (including spelling) as part of measured writing quality, so the direct influence of word-level literacy skills on quality probably indicates that more proficient phonological and orthographic processing frees up cognitive resources for other aspects of composing, which is in line with extant research (e.g., [46]). Two, stronger component literacy skills are associated with increased typing fluency, which in turn is related to higher text generation fluency, and finally these together positively impact typewritten paper quality. Again, we believe this demonstrates how stronger foundation literacy skills reduce the total cognitive load associated with writing, permitting students to divert adequate resources for transcription and text generation fluency while composing on the computer.

Most importantly, we found that, regardless of genre, handwriting fluency had a significant serial indirect effect on writing quality via typing fluency then text generation fluency (and via text generation fluency alone), though no significant direct effect, when controlling for word-level literacy skills. Overall, a one standard deviation change in handwriting fluency corresponded to about a one-fifth to a one-third standard deviation change in writing quality, and about $64-96 \%$ of that change was due to indirect effects, depending on the genre. Though the effects of handwriting fluency on computer-generated paper quality are indirect, mediated by more proximal writing fluency factors, namely typing fluency and text generation fluency, the fact that handwriting fluency matters even when composing on the computer elevates the importance of this aspect of transcription regardless of mode and adds to limited findings regarding cross-modal effects of transcription on writing quality [20]. 
The indirect manner in which handwriting fluency transmits its effects to writing quality is anticipated for students in late elementary grades; we may have very well observed direct effects if we had sampled younger students for whom transcription is far less automatized cf. [13,22-24]. The indirect path between handwriting fluency, text generation fluency, and writing quality deserves special mention. Scholars have posited that greater transcription fluency, especially handwriting fluency (in older students in particular), permits higher-level writing processes to occur more efficiently and effectively during the parallel processing required for most writing tasks [54], whether measured by duration of written language production bursts [55-57] or simply writing productivity or quality [11]. Our finding that handwriting fluency transmits its effects on quality not only through typing fluency then text generation fluency (as typing fluently permits one to produce more text in a given period of time) but also just through text generation fluency complements this account of the special influence of handwriting on composition. Overall, we see not only greater graphomotor fluency across modes of transcription leads to higher quality typed papers, but also more fluent transcription by hand, with its putative deep connections to other lower- and higher-level linguistic processes [15], benefits text generation fluency, which itself results in better quality typed papers. Students who develop strong proficiency with handwriting in elementary school, where most writing tasks still employ inscription using a stylus (e.g., [58]), have probably accumulated greater flexibility with diverting cognitive effort to idea generation and language formulation (text generation) for many writing tasks, including those using a keyboard.

As anticipated, the existence of relations between antecedent and consequent variables in our models was largely unaffected by genre, except for opinion writing quality, which appeared to rely more heavily on typing fluency whether the focal antecedent was word-level literacy component skills or handwriting fluency. This particular finding needs to be replicated, and we have no immediately discernible rationale for it. More directly to the issue of whether genre impacted the strength of the observed relations, we did find that informative writing had the largest associated indirect effects regardless of whether handwriting fluency or word-level written language was the focal antecedent variable. Informative papers were significantly shorter than narrative or opinion papers (though qualitative differences across genres were not observed), suggesting that our informative writing task, one in which students had to read and listen to a passage about an unfamiliar topic and share what they learned from the passage in their papers, was likely the most challenging for the children in our study. Our finding of stronger indirect effects for informative writing implies that lower-level skills (both word-level literacy and transcription skills) are mediated to a greater extent by higher-level (text generation) skills, and this is consistent with the hypothesis of Olive et al. [47], who suggested that less familiar, more challenging writing tasks place a premium on higher-level cognitive and linguistic skills and consequently will yield weaker relations between lower-level skills and quality.

As with any study, ours possesses several significant limitations. First, we did not counterbalance the administration of the handwriting and typing fluency tasks (handwriting fluency always was measured prior to typing fluency). It is possible that order effects influenced the students' performance on these tasks. We elected to have students complete the handwritten paragraph copy task first along with other paper and stylus tasks to streamline our group administration procedures. The typewritten paragraph copy task was administered at least a week later, so we believe recall of the paragraph had little influence on the results. Second, we did not collect samples of handwritten papers by students-this made it impossible to fully evaluate the cross-modal effects of transcription and text generation fluency. However, this was not the main purpose of our study and our findings still contribute meaningfully to the small body of work on this topic. Third, our writing performance task is confounded with fluency due to the timed nature of the task. It is likely students would have written longer and qualitatively superior papers had they been provided with more time. Nevertheless, we do not have reason to believe this would have altered the relationships between the antecedent and consequent variables we investigated. Finally, we did not include sentence- or discourse-level language 
and literacy components in our models. Thus, we cannot determine if our results would replicate with a more robust accounting of known influences on writing outcomes. In the context of our study, it is possible that the effects of word-level literacy skills and graphomotor fluency on writing quality would be muted if higher-level skills had been included. Our models accounted for anywhere between $45 \%$ and $61 \%$ of variance in writing quality, leaving ample variance unexplained. Even so, our results are largely consistent with theory and prior research findings [22]. Additionally, because we separate the effects of transcription (spelling and graphomotor fluency) from text generation in this study, we believe, in fact, we do account to some extent for lower-level and higher-level component writing skills, albeit without the precision afforded by a comprehensive array of component skills measures.

\section{Conclusions}

Our results highlight the importance of graphomotor fluency, which tends to be ignored or treated as a nuisance with minimal attention by educators, for writing performance in two ways. First, greater handwriting fluency permits more cognitive resources to be devoted to text generation fluency (i.e., efficiently generating ideas and translating them into appropriate and effective language), which is essential for good writing. This appears to be the case even when a student composes using a word processor, which involves somewhat different visual-proprioceptive integration and motor planning and execution processes for transcription by keyboard. It is likely the unique connections between handwriting and other cognitive resources and processes relied upon when writing are at play. Second, greater handwriting fluency is related to greater writing fluency more broadly, as more fluent handwriting is associated with better typing fluency (they both are fundamentally graphomotor tasks) and thus typed text generation fluency, which is related because a student is constrained when composing on the computer within time limits by how fast they can type.

We observed that students in our sample who were identified with disabilities (approximately $10 \%$ ) exhibited not only significantly poorer word-level literacy skills, but also less fluent transcription across modes and poorer writing quality across genres. However, their texts were not significantly shorter for the opinion and informative writing tasks. This may indicate these students did not have as much difficulty with text generation fluency as they did with transcription fluency, which highlights the importance of transcription for students with writing difficulties $[59,60]$. Handwriting must be explicitly taught to students, particularly those with writing problems, despite such instruction having low status [61] and teachers feeling ill-prepared to teach handwriting [58]. The benefits of such instruction on student writing outcomes even beyond handwriting fluency and legibility are well documented $[1,16,62,63]$.

Looking across all participants in our study, students were significantly more fluent when transcribing by hand than by keyboard, and both of these facets of graphomotor fluency were predictive of writing output and quality, reinforcing the idea that not only handwriting, but keyboarding also must be explicitly taught so that students become proficient with composing on the computer. We should note that, on average, the students in our sample could copy text at a rate of approximately 70 characters $/ \mathrm{min}$ by hand and 60 characters/min by keyboard, which is roughly equivalent to 17.5 words/min and 15 words/min, respectively, based on an average of four characters per word in the paragraph we used. Thus, the students in our sample, on average, were relatively fluent with transcription in either mode compared with extant data. For instance, Graham and Miller [64] found that students in grades 4 through 6 can copy text by hand at a rate of 7 to 10 words/min and Graves [65] found a range of 8 to 19 words/min for 9 - and 10-year-olds when composing by hand. Without keyboarding instruction, students in these grades can generally type 3 to 5 words/min [66], but with instruction, students can increase their typing speed to around $10-12$ words/min or greater $[67,68]$.

To reiterate, our study findings suggest the following three educational implications. First, educators should employ with consistency and fidelity evidence-based instructional practices to address component literacy skills such as vocabulary knowledge and word-level decoding and encoding skills, as a strong foundation in such component skills appears to free up cognitive resources needed for 
transcription and text generation during writing activities, especially activities that involve less familiar discourse structures. Second, explicit and systematic handwriting instruction in the primary grades (K-3) is vital to a strong performance in writing tasks, regardless of whether the text is composed on the computer or on paper, in part because attaining fluent handwriting reinforces the development of other language and literacy skills. Likewise, for students to compose successfully using a computer or other digital device, they must possess adequately fluent keyboarding skills. Fluent handwriting and typing skills appear to be especially important for children with disabilities, as these children appear to struggle more with transcription than text generation, at least in our study sample. Third, because the writing quality depends on students' graphomotor fluency (i.e., fluent handwriting and typing) and their text generation fluency (i.e., fluent translation of thoughts into acceptable language), instruction that aims to integrate these two aspects of writing may prove to be beneficial.

Author Contributions: Conceptualization, G.A.T.; methodology, G.A.T.; formal analysis, G.A.T. and F.L.; investigation, G.A.T., K.G., and H.L.R.; data curation, G.A.T., J.S.B., K.G., and H.R.; writing-original draft preparation, G.A.T. and J.S.B.; writing-review and editing, G.A.T., J.S.B., K.G., and H.L.R.; project administration, G.A.T.; funding acquisition, G.A.T. and F.L. All authors have read and agreed to the published version of the manuscript.

Funding: This research was supported in part by grant \#R305A160049 from the U.S. Department of Education, Institute of Education Sciences, to Michigan State University. Statements do not necessarily reflect the positions or policies of this agency, and no official endorsement by it should be inferred.

Acknowledgments: We wish to thank the teachers and students who participated in this research project as well as the following undergraduate research assistants who spent many hours scoring the standardized tests and writing samples: Taylor Arnold, Mikayla Kalik, Amanda Ling, and Nicole Steele.

Conflicts of Interest: The authors declare no conflict of interest. The funder had no role in the design of the study; in the collection, analyses, or interpretation of data; in the writing of the manuscript, or in the decision to publish the results.

\section{References}

1. Berninger, V.W.; Amtmann, D. Preventing written expression disabilities through early and continuing assessment and intervention for handwriting and/or spelling problems. Research into practice. In Handbook of Learning Disabilities; Swanson, H.L., Harris, K.R., Graham, S., Eds.; Guilford Press: New York, NY, USA, 2003; pp. 345-363.

2. Berninger, V.W.; Chanquoy, L. What writing is and how it changes across early and middle childhood development: A multidisciplinary perspective. In Writing: A Mosaic of New Perspectives; Grigorenko, E., Mambrino, E., Preiss, D., Eds.; Psychology Press: New York, NY, USA, 2012; pp. 65-84.

3. Berninger, V.W.; Vaughan, K.; Abbott, R.D.; Begay, K.; Coleman, K.B.; Curtin, G.; Hawkins, J.M.; Graham, S. Teaching spelling and composition alone and together: Implications for the simple view of writing. J. Ed. Psychol. 2002, 94, 291-304. [CrossRef]

4. Berninger, V.W.; Swanson, H.L. Modifying Hayes and Flower's model of skilled writing to explain beginning and developing writing. In Advances in Cognition and Educational Practice: Children's Writing: Toward a Process Theory of the Development of Skilled Writing; Butterfield, E.C., Ed.; JAI Press: Greenwich, CT, USA, 1994; Volume 2, pp. 57-82.

5. Alamargot, D.; Fayol, M. Modelling the development of written composition. In Handbook of Writing Development; Beard, R., Myhill, D., Nystrand, M., Riley, J., Eds.; Sage: London, UK, 2009; pp. $23-47$.

6. Kim, Y.G.; Park, S. Unpacking pathways using the direct and indirect effects model of writing (DIEW) and the contributions of higher order cognitive skills to writing. Read. Writ. 2019, 32, 1319-1343. [CrossRef]

7. Olive, T.; Kellogg, R.T.; Piolat, A. Verbal, visual, and spatial working memory demands during text composition. Appl. Psycholinguist 2008, 29, 669-687. [CrossRef]

8. VanDrempt, N.; McCluskey, A.; Lannin, N.A. A review of factors that influence adult handwriting performance. Aust. Occup. Ther. J. 2011, 58, 321-328. [CrossRef] [PubMed]

9. Bourdin, B.; Fayol, M. Even in adults, written production is still more costly than oral production. Int. J. Psychol. 2002, 37, 219-227. [CrossRef] 
10. Feng, L.; Lindner, A.; Ji, S.R.; Joshi, R.M. The roles of handwriting and keyboarding in writing: A meta-analytic review. Read. Writ. 2019, 32, 33-63. [CrossRef]

11. Graham, S.; Berninger, V.W.; Abbott, R.; Abbott, S.; Whitaker, D. Role of mechanics in composting of elementary school students: A new methodological approach. J. Ed. Psychol. 1997, 89, 170-182. [CrossRef]

12. Jones, D.; Christensen, C.A. The relationship between automaticity in handwriting and students' ability to generate written text. J. Ed. Psychol. 1999, 91, 44-49. [CrossRef]

13. Kent, S.C.; Wanzek, J. The relationship between component skills and writing quality and production across developmental levels: A meta-analysis of the last 25 years. Rev. Ed. Res. 2016, 86, 570-601. [CrossRef]

14. Puranik, C.S.; Al Otaiba, S. Examining the contribution of handwriting and spelling to written expression in kindergarten children. Read. Writ. 2012, 25, 1523-1546. [CrossRef]

15. Wagner, R.K.; Puranik, C.S.; Foorman, B.; Foster, E.; Wilson, L.G.; Tschinkel, E.; Kantor, P.T. Modeling the development of written language. Read. Writ. 2011, 24, 203-220. [CrossRef] [PubMed]

16. Graham, S.; McKeown, D.; Kiuhara, S.; Harris, K.R. A meta-analysis of writing instruction for students in the elementary grades. J. Ed. Psychol. 2012, 104, 879-896. [CrossRef]

17. Graham, S.; Santangelo, T. Does spelling instruction make students better spellers, readers, and writers? A meta-analytic review. Read. Writ. 2014, 27, 1703-1743. [CrossRef]

18. Santangelo, T.; Graham, S. A comprehensive meta-analysis of handwriting instruction. Ed. Psychol. Rev. 2016, 28, 225-265. [CrossRef]

19. Christensen, C.A. The role of orthographic-motor integration in the production of creative and well-structured written text for students in secondary school. Ed. Psychol. 2005, 25, 441-453. [CrossRef]

20. Connelly, V.; Gee, D.; Walsh, E. A comparison of keyboarded and handwritten compositions and the relationship with transcription speed. Br. J. Ed. Psychol. 2007, 77, 479-492. [CrossRef]

21. Shorter, L.L. Keyboarding Versus Handwriting: Effects on the Composition Fluency and Composition Quality of Third Grade Students; University of South Alabama: Mobile, AL, USA, 2001.

22. Kim, Y.G.; Schatschneider, C. Expanding the developmental models of writing: A direct and indirect effects model of developmental writing (DIEW). J. Ed. Psychol. 2017, 109, 35-50. [CrossRef]

23. Limpo, T.; Alves, R.A. Modeling writing development: Contribution of transcription and self-regulation to Portuguese students' text generation quality. J. Ed. Psychol. 2013, 105, 401-413. [CrossRef]

24. Limpo, T.; Alves, R.A.; Connelly, V. Examining the transcription-writing link: Effects of handwriting fluency and spelling accuracy on writing performance via planning and translating in middle grades. Learn. Ind. Differ. 2017, 53, 26-36. [CrossRef]

25. Berninger, V.W.; Abbott, R.D.; Jones, J.; Wolf, B.J.; Gould, L.; Anderson-Youngstrom, M.; Shimada, S.; Apel, K. Early development of language by hand: Composing, reading, listening, and speaking connections; three letter-writing modes; and fast mapping in spelling. Dev. Neuropsychol. 2006, 29, 61-92. [CrossRef]

26. Rogers, J.; Case-Smith, J. Relationships between handwriting and keyboarding performance of sixth-grade students. Am. J. Occup. Ther. 2002, 56, 34-39. [CrossRef] [PubMed]

27. Cohen, M.R.; Wicklund, D.A. Component abilities of spelling, memory, and motor skill in novices' transcription typing. Percept. Mot. Ski. 1990, 70, 19-31. [CrossRef]

28. Jiménez, J.E.; Hernández-Cabrera, J.A. Transcription skills and written composition in Spanish beginning writers: Pen and keyboard modes. Read. Writ. 2019, 32, 1847-1879. [CrossRef]

29. Longcamp, M.; Boucard, C.; Gilhodes, J.-C.; Velay, J.-L. Remembering the orientation of newly learned characters depends on the associated writing knowledge: A comparison between handwriting and typing. Hum. Mov. Sci. 2006, 25, 646-656. [CrossRef] [PubMed]

30. Longcamp, M.; Boucard, C.; Gilhodes, J.-C.; Anton, J.L.; Roth, M.; Nazarian, B.; Velay, J.-L. Learning through hand- or typewriting influences visual recognition of new graphic shapes: Behavioral and functional imaging evidence. J. Cogn. Neurosci. 2008, 20, 802-815. [CrossRef]

31. Longcamp, M.; Zerbato-Poudou, M.-T.; Velay, J.-L. The influence of writing practice on letter recognition in preschool children: A comparison between handwriting and typing. Acta Psychol. 2005, 119, 67-79. [CrossRef]

32. Longcamp, M.; Tanskanen, T.; Hari, R. The imprint of action: Motor cortex involvement in visual perception of handwritten letters. NeuroImage 2006, 33, 681-688. [CrossRef]

33. Mangen, A. The disappearing trace and the abstraction of inscription in digital writing. In Exploring Technology for Writing and Writing Instruction; Pytash, K., Ferdig, R., Eds.; IGI Global: Hershey, PA, USA, 2014; pp. 100-113. 
34. Mangen, A.; Velay, J.-L. Digitizing literacy: Reflections on the haptics of writing. In Advances in Haptics; Zadeh, M.H., Ed.; InTech: Rijeka, Croatia, 2010; pp. 385-402.

35. Abbott, R.D.; Berninger, V.W. Structural equation modeling of relationships among developmental skills and writing skills in primary- and intermediate-grade writers. J. Ed. Psychol. 1993, 85, 478-508. [CrossRef]

36. Berninger, V.; Abbott, R.; Abbott, S.; Graham, S.; Richards, T. Writing and reading: Connections between language by hand and language by eye. J. Learn. Dis. 2002, 35, 39-56. [CrossRef]

37. Ahmed, Y.; Wagner, R.K.; Lopez, D. Developmental relations between reading and writing at the word, sentence and text levels: A latent change score analysis. J. Ed. Psychol. 2014, 106, 419-434. [CrossRef]

38. Abbott, R.D.; Berninger, V.W.; Fayol, M. Longitudinal relationships of levels of language in writing and between writing and reading in grades 1 to 7. J. Ed. Psychol. 2010, 102, 281-298. [CrossRef]

39. Graham, S.; Hebert, M. Writing to read: A meta-analysis of the impact of writing and writing instruction on reading. Harv. Ed. Rev. 2011, 81, 710-744. [CrossRef]

40. Shanahan, T. Relations among oral language, reading, and writing development. In Handbook of Writing Research; MacArthur, C.A., Graham, S., Fitzgerald, J., Eds.; Guilford Press: New York, NY, USA, 2006; pp. 171-183.

41. Mehta, P.; Foorman, B.; Branum-Martin, L.; Taylor, W. Literacy as a unidimensional multilevel construct: Validation, sources of influence, and implications in a longitudinal study in grades 1 to 4 . Sci. Stud. Read. 2005, 9, 85-116. [CrossRef]

42. Grobe, G. Syntactic maturity, mechanics, and vocabulary as predictors of quality ratings. Res. Teach. Engl. 1981, 15, 75-85.

43. Olinghouse, N.G.; Leaird, J.T. The relationship between measures of vocabulary and narrative writing quality in second- and fourth-grade students. Read. Writ. 2009, 22, 545-565. [CrossRef]

44. Olinghouse, N.G.; Wilson, J. The relationship between vocabulary and writing quality in three genres. Read. Writ. 2013, 26, 45-65. [CrossRef]

45. Hayes, J.R. A new framework for understanding cognition and affect in writing. In The Science of Writing: Theories, Methods, Individual Differences, and Applications; Levy, C.M., Randall, S., Eds.; Erlbaum: Mahwah, NJ, USA, 1996; pp. 1-27.

46. McCutchen, D. Knowledge, processing, and working memory: Implications for a theory of writing. Ed. Psychol. 2000, 35, 13-23. [CrossRef]

47. Olive, T.; Favart, M.; Beauvais, C.; Beauvais, L. Children's cognitive effort and fluency in writing: Effects of genre and of handwriting automatisation. Learn. Instr. 2009, 19, 299-308. [CrossRef]

48. Wilkinson, G.S. WRAT-3: The Wide Range Achievement Test, 3rd ed.; Wide Range, Inc.: Wilmington, DE, USA, 1993.

49. Hammill, D.D.; Larsen, S.C. Test of Written Language, 4th ed.; PRO-ED: Austin, TX, USA, 2009.

50. Monroe, M.; Sherman, E. Group Diagnostic Reading Aptitude and Achievement Tests; C. H. Nevins Printing Co.: Bradenton, FL, USA, 1966.

51. Troia, G.A.; Harbaugh, A.G.; Shankland, R.K.; Wolbers, K.A.; Lawrence, A.M. Relationships between writing motivation, writing activity, and writing performance: Effects of grade, sex, and ability. Read. Writ. 2013, 26, 17-44. [CrossRef]

52. Truckenmiller, A.J.; McKindles, J.V.; Petscher, Y.; Eckert, T.L.; Tock, J. Expanding curriculum-based measurement in written expression for middle school. J. Spec. Ed. 2020, 54, 133-145. [CrossRef]

53. Hayes, A.F. Introduction to Mediation, Moderation, and Conditional Process Analysis: A Regression-Based Approach, 2nd ed.; Guilford Press: New York, NY, USA, 2018.

54. Olive, T.; Kellogg, R.T. Concurrent activation of high- and low-level production processes in written composition. Mem. Cogn. 2002, 30, 594-600. [CrossRef] [PubMed]

55. Alves, R.A.; Branco, M.; Castro, S.L.; Olive, T. Effects of handwriting skill, handwriting and dictation modes, and gender of fourth graders on pauses, written language bursts, fluency, and quality. In Past, Present, and Future Contributions of Cognitive Writing Research to Cognitive Psychology; Berninger, V.W., Ed.; Psychology Press: New York, NY, USA, 2012; pp. 389-402.

56. Alves, R.A.; Limpo, T. Progress in written language bursts, pauses, transcription, and written composition across schooling. Sci. Stud. Read. 2015, 19, 374-391. [CrossRef]

57. Alves, R.A.; Limpo, T.; Fidalgo, R.; Carvalhais, L.; Pereira, L.A.; Castro, S.L. The impact of promoting transcription on early text production: Effects on bursts and pauses, levels of written language, and writing performance. J. Ed. Psychol. 2016, 108, 665-679. [CrossRef] 
58. Gilbert, J.; Graham, S. Teaching writing to elementary students in grades 4-6: A national survey. Elem. Sch. J. 2010, 110, 494-518. [CrossRef]

59. Berninger, V.W.; Winn, W.D. Implications of advancements in brain research and technology for writing development, writing instruction, and educational evolution. In Handbook of Writing Research; MacArthur, C.A., Graham, S., Fitzgerald, J., Eds.; Guilford Press: New York, NY, USA, 2006; pp. 96-114.

60. Graham, S.; Harris, K.R. The role of self-regulation and transcription skills in writing and writing development. Ed. Psychol. 2000, 35, 3-12. [CrossRef]

61. Medwell, J.; Wray, D. Handwriting-A forgotten language skill? Lang. Ed. 2008, 22, 34-47. [CrossRef]

62. Feder, K.P.; Majnemer, A. Handwriting development, competency, and intervention. Dev. Med. Child. Neurol. 2007, 49, 312-317. [CrossRef] [PubMed]

63. Yancosek, K.E.; Howell, D. Systematic review of interventions to improve or augment handwriting ability in adult clients. OTJR 2011, 31, 55-63. [CrossRef]

64. Graham, S.; Miller, L. Handwriting research and practice: A unified approach. Focus Except. Child. 1980, 13, 1-16. [CrossRef]

65. Graves, D.H. Writing: Teachers and Children at Work; Heinemann: Exeter, NH, USA, 1983.

66. Wetzel, K. Keyboarding skills: Elementary, my dear. Comput. Teach. 1985, 12, 15-19.

67. Nichols, L. A comparison of two methods for teaching keyboarding in the elementary school. Comput. Sch. 1995, 11, 15-25. [CrossRef]

68. Sormunen, C. Elementary school keyboarding: A case for skill development. Bus. Ed. Forum 1991, 45, 28-30.

Publisher's Note: MDPI stays neutral with regard to jurisdictional claims in published maps and institutional affiliations.

(C) 2020 by the authors. Licensee MDPI, Basel, Switzerland. This article is an open access article distributed under the terms and conditions of the Creative Commons Attribution (CC BY) license (http://creativecommons.org/licenses/by/4.0/). 